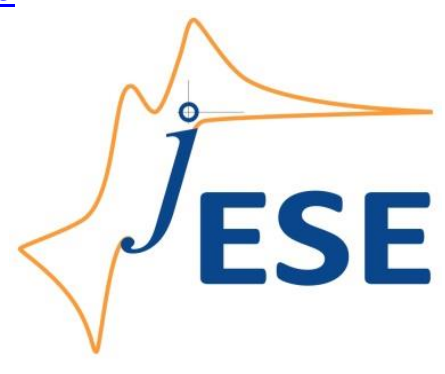

Open Access: ISSN 1847-9286

www.jESE-online.org

Original scientific paper

\title{
Synthesis and characterization of a novel non-enzymatic glucose biosensor based on polyaniline/zinc oxide/multi-walled carbon nanotube ternary nanocomposite
}

\author{
Soha Mohajeri ${ }^{\bowtie}$, Abolghassem Dolati ${ }^{\circledR}$, Khashayar Yazdanbakhsh \\ Department of Materials Science and Engineering, Sharif University of Technology, Azadi Ave., \\ P.O. Box 11155-9466, Tehran, Iran
}

Corresponding authors: ${ }^{\square}$ smohajeri@alum.sharif.edu; ${ }^{\circledR}$ dolati@sharif.edu

Received: February 17, 2019; Revised: March 28, 2019; Accepted: March 28, 2019

\begin{abstract}
Novel polyaniline/zinc oxide/multi-walled carbon nanotube (PANI/ZnO/MWCNT) ternary nanocomposite was fabricated as a non-enzymatic glucose biosensor. Thermal chemical vapor deposition (CVD) process was employed to synthesize vertically aligned MWCNTs on stainless steel substrates coated by Co catalyst nanoparticles. In order to fabricate sensitive and reliable MWCNT-based biosensors, nanotubes density and alignment were adjusted by varying the CVD reaction time and cobalt sulfate concentration. The fabricated nanotubes were modified by $\mathrm{ZnO}$ particles through the potentiostatic electrodeposition technique. Optimal electrodeposition potential, electrodeposition time, and electrolyte concentration values were determined. The optimized ZnO/MWCNT nanocomposite was reinforced by polyaniline (PANI) nanofibers through the potential cycling technique, and the morphology, elemental composition, and phase structure of the fabricated nanocomposites were characterized by scanning electron microscopy (SEM), energy dispersive X-ray spectroscopy $(E D X)$, and $X$-ray diffraction (XRD), respectively. The sensing mechanism of the PANI/ZnO/MWCNT electrode for the electrochemical detection of glucose was investigated, and the limit of detection and sensitivity values of the designed sensor were determined. The fast response time of the ternary nanocomposite-based sensor as well as its satisfactory stability and reproducibility, makes it a promising candidate for non-enzymatic detection of glucose in biomedical, environmental, and industrial applications.

Keywords

Multi-walled carbon nanotubes; zinc oxide nanoparticles; polyaniline nanofibers; electrodeposition; non-enzymatic glucose sensor
\end{abstract}




\section{Introduction}

Electrocatalytic oxidation of glucose is of crucial importance not only to clinical diagnostic applications, but also to the ecological fields, wastewater treatment, and food industries [1-4]. The most commonly used amperometric glucose detectors are enzymatic biosensors in which glucose oxidase enzyme catalyzes the oxidation of glucose to gluconolactone [5]. However, due to the intrinsic nature of enzymes, such enzyme-based sensors are susceptible to variations in $\mathrm{pH}$, temperature, humidity, and toxic chemicals, and simultaneously suffer from instability, high cost, and complex immobilization procedures [6]. Thus, considerable attempts were made to develop economical, highly sensitive, fast and reliable non-enzymatic glucose sensors [7]. The enzyme-free detection of glucose on noble metals, thin film alloys, and metallic nanoparticles was extensively explored; however, these sensors undergo surface poisoning by adsorbed intermediates, leading to their poor sensitivity, selectivity, and stability [8-10]. Nevertheless, non-enzymatic electrochemical glucose sensors based on carbon nanomaterials, particularly carbon nanotubes and graphene, have attracted huge attention due to their unique properties including high surface area, chemical and electrochemical stability, exceptional electrical conductivity, superior biocompatibility, and ease of modification [11,12]. As compared to traditional electrodes, multi-walled carbon nanotubes (MWCNT) based electrochemical sensors present lower charge-transfer resistance, faster response time, and higher sensitivity for the direct oxidation of glucose owing to their one-dimensional hollow tubular nanochemistry [13]. High-quality and well-aligned MWCNT arrays can be fabricated by thermal chemical vapor deposition (CVD) process which is uniquely superior to the other synthesis methods of carbon nanotubes such as arc discharge and laser-ablation. This method involves the catalytic decomposition of a gaseous carbon precursor at an elevated temperature on the surface of a substrate coated with transition catalysts such as iron, cobalt, or nickel [14]. To gain greater control over the performance of the MWCNT-based electrochemical sensors, low-density vertically aligned MWCNT forests can be synthesized by adjusting the CVD reaction time, temperature, pressure, gas flow rate, nature of the metal catalyst, concentration of the catalyst precursor, and so forth [15]. Recently, various modified carbon nanotube electrodes have been prepared and utilized for biosensing applications [16,17], among which MWCNT-based sensors modified with zinc oxide as an electroactive metal oxide have been the subject of much interest [18]. ZnO nanostructures can be efficiently applied for the modification of MWCNT-based glucose biosensors as they possess extraordinary properties including biocompatibility, nontoxicity, high electrochemical activity, intrinsic hydrophilicity, chemical and photochemical stability [19]. Moreover, MWCNT can be modified by conducting polymers to take advantage of their synergic effect, and significantly enhance electrochemical activity and sensitivity of the modified sensing platform [20]. Polyaniline (PANI) is exceptionally unique among the class of conducting polymers, and it has been extensively applied in electrochemical sensors by virtue of its excellent conductivity, environmental stability, high polymerization yield, and low cost [21]. Although both ZnO/MWCNT and PANI/MWCNT nanocomposites have been studied for enzymatic glucose detection, none of these binary hybrid materials have been examined as non-enzymatic glucose biosensors. Moreover, no report is available on the development of PANI/ZnO/MWCNT ternary nanocomposite as an electrochemical biosensor with enhanced sensitivity towards the enzyme-free glucose detection. In the current study, we combined the advantageous features and synergetic effects of MWCNT, ZnO, and PANI with the aim of the direct electrochemical oxidation of glucose in alkaline medium. Firstly, lowdensity vertically aligned MWCNT-based electrodes were fabricated by thermal CVD process and subsequently, the synthesized nanotubes were modified by $\mathrm{ZnO}$ nanoparticles and PANI nanofibers 
via potentiostatic electrodeposition and in-situ electropolymerization techniques, respectively. The objective of this paper was to optimize the process parameters in order to synthesize PANI/ZnO/MWCNT ternary nanocomposite with an optimal morphological structure and enhanced electrocatalytic performance towards glucose sensing. Furthermore, this study aimed to explore the sensitivity, detection limit, response time, stability, and reproducibility of the developed biosensor for non-enzymatic glucose detection in alkaline electrolytes.

\section{Experimental}

Stainless steel type 304 substrates were polished to a 1200 grit finish with SiC abrasive paper, degreased with alcohol, and ultrasonically rinsed in distilled water. In order to activate the surface of the stainless steel and remove the passive protective chromium oxide layer, the substrates were treated in $9 \mathrm{M}$ sulfuric acid solution $\left(\mathrm{H}_{2} \mathrm{SO}_{4} 98 \%\right.$, Merck) for $10 \mathrm{~min}$. Prior to the synthesis of carbon nanotubes, thin cobalt layers were deposited onto the substrates from aqueous solutions containing various concentrations of $\mathrm{CoSO}_{4} \cdot 7 \mathrm{H}_{2} \mathrm{O}(0.01,0.05,0.1,0.15$, and $0.25 \mathrm{M}), 1 \mathrm{M} \mathrm{Na}_{2} \mathrm{SO}_{4}, 0.5 \mathrm{M} \mathrm{H}_{3} \mathrm{BO}_{3}$, and double distilled water. All reagents were analytical grade purchased from Merck. A typical threeelectrode cell consisting of a $0.5 \times 0.5 \mathrm{~cm}^{2}$ stainless steel plate as the working electrode, a $2 \times 1 \mathrm{~cm}^{2}$ platinum plate as the counter electrode, and a saturated calomel electrode (SCE) as reference was employed. Electrodeposition was conducted at $25^{\circ} \mathrm{C}$ using an EG\&G PAR potentiostat model 273A at the potential of $-1.1 \mathrm{~V}$ for $2 \mathrm{~s}$. Vertically aligned multi-walled carbon nanotubes (MWCNT) were synthesized by thermal chemical vapor deposition (CVD) of ethylenediamine as a precursor. For this purpose, cobalt-coated substrates were placed in the middle of a $50 \mathrm{~mm}$ diameter quartz tube reactor of $1100 \mathrm{~mm}$ length which was preheated to $750{ }^{\circ} \mathrm{C}$. Simultaneously, to prevent the oxidation of the cobalt film, the reactor was purged by $\mathrm{N}_{2}$ gas. Thereafter, ethylenediamine was introduced into the quartz tube at a flow rate of $400 \mathrm{~mL} \mathrm{~min}^{-1}$ while $\mathrm{N}_{2}$ was being bubbled through the ethylenediamine container. Ultimately, after two different reaction times of 20 and $30 \mathrm{~min}$, the reactor was cooled down to room temperature under an inert nitrogen atmosphere, and MWCNTs were fabricated. In order to investigate the influence of various cobalt sulfate concentrations and CVD reaction times on the morphology and density of the developed nanotubes, a TESCAN VEGA II scanning electron microscope (SEM) was employed and the optimal operating parameters were determined. The electrodeposition of ZnO on low-density vertically aligned MWCNT was conducted using an Autolab PGSTAT302N system in a conventional three-electrode configuration, where a MWCNT-coated electrode, a platinum wire, and saturated calomel electrode (SCE) served as working, counter, and reference electrodes, respectively. ZnO/MWCNT composites were synthesized in electrolytes containing different concentrations of $\mathrm{Zn}\left(\mathrm{NO}_{3}\right)_{2}(0.025,0.05 \mathrm{M})$ and $\mathrm{KCl}(0.05,0.1 \mathrm{M})$ by applying various deposition potentials $(-0.15,-1,-1.5,-1.8 \mathrm{~V})$ for different durations (10 and $20 \mathrm{~min}$ ), and the optimum process parameters were ascertained through the morphological analyses. The optimized ZnO/MWCNT nanocomposite was reinforced with polyaniline (PANI) nanofibers by immersing the electrode in a solution containing $0.025 \mathrm{M}$ aniline $\left(\mathrm{C}_{6} \mathrm{H}_{5} \mathrm{NH}_{2} 99 \%\right.$, Sigma Aldrich) and $0.25 \mathrm{M}$ sulfuric acid $\left(\mathrm{H}_{2} \mathrm{SO}_{4} 98 \%\right.$, Merck), and sweeping the potential for 6 cycles between of -0.2 to $+0.8 \mathrm{~V}$ vs. SCE at a rate of $50 \mathrm{mV} \mathrm{s}^{-1}$. The obtained PANI/ZnO/MWCNT electrode was subsequently dried at ambient temperature and its morphology was examined by SEM. The elemental composition and phase structure of the optimized ZnO/MWCNT and PANI/ZnO/MWCNT nanocomposites were analyzed by energy dispersive X-ray spectroscopy (EDX, Shimadzu 720/800HS/900HS) and X-ray diffraction (XRD, Philips PW-3040), respectively. The sensing properties of the fabricated electrodes were assessed towards the detection of glucose in alkaline media. Electrochemical experiments were carried out via 
an EG\&G PAR potentiostat model 273A in a three-electrode cell including the unmodified MWCNT, $\mathrm{ZnO} / \mathrm{MWCNT}$, or PANI/ZnO/MWCNT electrode as the working electrode, a platinum wire as the counter electrode, and SCE as reference. The electrolyte contained different concentrations of sodium hydroxide ( $\mathrm{NaOH} 98 \%$, Merck) and glucose $\left(\mathrm{C}_{6} \mathrm{H}_{12} \mathrm{O}_{6} 99.5 \%\right.$ Sigma-Aldrich). Cyclic voltammetry (CV) and linear sweep voltammetry (LSV) tests were carried out in the range of 0 to $1.5 \mathrm{~V}$ for various $\mathrm{NaOH}$ concentrations (10-300 mM), scan rates (10-500 $\mathrm{mV} \mathrm{s}^{-1}$ ) and glucose concentrations (0.1-6 mM). The oxidation mechanism of glucose at the fabricated sensors was identified, and the sensitivity and detection limit of the PANI/ZnO/MWCNT electrochemical biosensor were measured. The response time of the ternary nanocomposite-based biosensor was estimated through amperometric measurements, and its stability and reproducibility were evaluated.

\section{Results and discussion}

\section{Influence of different operating parameters on the growth of MWCNT}

Cobalt nanoparticles deposited on the stainless steel substrates are efficient catalysts for the growth of MWCNT in good alignment by the chemical vapor deposition of ethylenediamine. While the thickness of the cobalt film determines the diameter and density of the vertically aligned MWCNT, the CVD reaction time controls the length of nanotubes [22]. Figure 1 displays the SEM images of MWCNT synthesized at $750{ }^{\circ} \mathrm{C}$ for $30 \mathrm{~min}$ on a stainless steel substrate at two different magnifications. Prior to the synthesis of MWCNT, a thin cobalt layer was electrodeposited as an active catalyst on the substrate at the potential of $-1.1 \mathrm{~V}$ for $2 \mathrm{~s}$ from a bath containing $0.25 \mathrm{M} \mathrm{CoSO}_{4}$ $\cdot 7 \mathrm{H}_{2} \mathrm{O}$. It can be observed that high concentration of cobalt sulfate in the deposition bath leads to the formation of a relatively thick Co film, where the growth of high-density MWCNT is favored. Moreover, since the CVD reaction time is prolonged to $30 \mathrm{~min}$, a relatively long forest of disordered MWCNT is produced, and the nanotubes are deformed and tangled together due to the local bending of their tips.

a

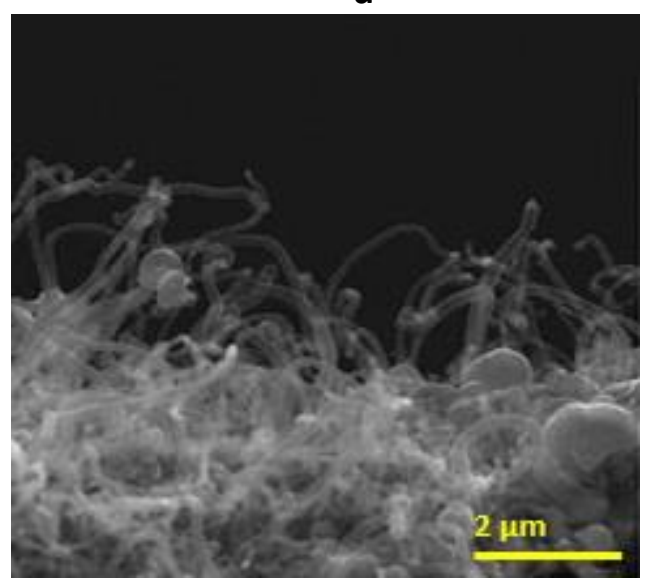

b

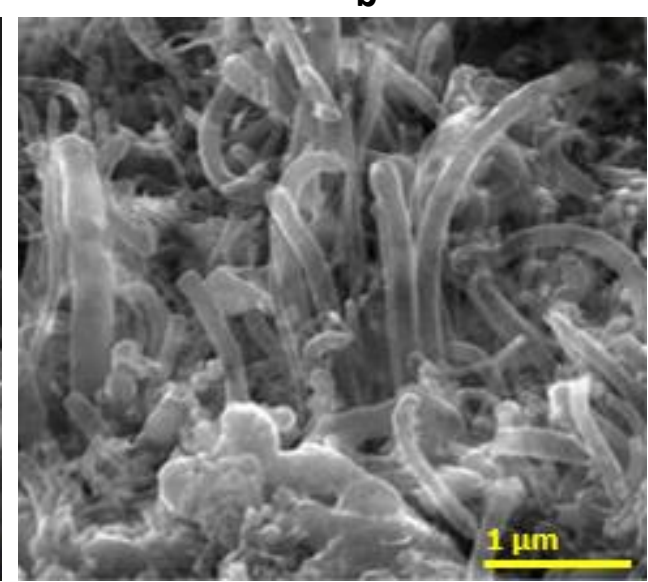

Figure 1. (a) low magnification and (b) high magnification SEM images of MWCNT grown on cobalt-coated stainless steel substrate at $750^{\circ} \mathrm{C}$ for $30 \mathrm{~min}$. Cobalt catalyst nanoparticles were electrodeposited at the potential of $-1.1 \mathrm{~V}$ vs. SCE for $2 \mathrm{~s}$ from a bath containing $0.25 \mathrm{M} \mathrm{CoSO}_{4} \cdot 7 \mathrm{H}_{2} \mathrm{O}$.

In order to fabricate sensitive and reliable MWCNT-based biosensors, it was crucial to carefully tune the density and alignment of MWCNTs. Thus, the cobalt sulfate concentration and CVD time were reduced while the deposition potential and deposition time of the cobalt film were kept constant at $-1.1 \mathrm{~V}$ and $2 \mathrm{~s}$, respectively. The SEM images of the fabricated nanotubes are shown in Figure 2. According to Figure $2 \mathrm{a}$, as the concentration of cobalt sulfide is deceased to $0.01 \mathrm{M}$ while 
the CVD reaction time is kept at $30 \mathrm{~min}$, the thickness of the deposited catalyst layer reduces, creating islands of randomly oriented MWCNT. Figure $2 \mathrm{~b}$ demonstrates that increasing the concentration of cobalt sulfide from 0.01 to $0.05 \mathrm{M}$ slightly enhances the distribution of nanotubes, but the alignment of MWCNT is still not satisfactory. With a further increase of the concentration to $0.15 \mathrm{M}$, although the alignment of MWCNT is substantially improved due to the formation of a highdensity MWCNT forest, there is not an appropriate spacing between neighbouring tubes (Figure 2c). This structure is not desirable for using MWCNT as electrochemical sensors and biosensors because the densely packed nanotubes will block the transfer of the electrons and increase the response time of the sensing platform. As depicted in Figure $2 \mathrm{~d}$, a concentration value between 0.05 and $0.15 \mathrm{M}$, i.e. $0.1 \mathrm{M}$, can decrease the density of active sites for the growth of low-density MWCNT and contribute to the synthesis of an aligned MWCNT forest. Besides, since the CVD reaction time is decreased from 30 to $20 \mathrm{~min}$, tubes of shorter height are fabricated and the distortion and bending of the tips are prevented. In this case, the average diameter and length of MWCNTs are estimated to be $100 \mathrm{~nm}$ and $2 \mu \mathrm{m}$, respectively. Thus, $\mathrm{CoSO}_{4} \cdot 7 \mathrm{H}_{2} \mathrm{O}$ concentration of $0.1 \mathrm{M}$ and the CVD reaction time of $20 \mathrm{~min}$ are selected as the optimal operating parameters for the fabrication of perfectly aligned arrays of low-density MWCNT for biosensing applications.

a

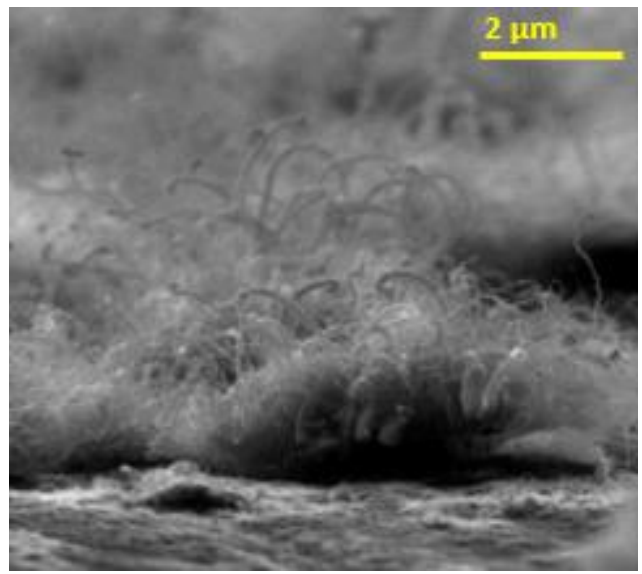

C

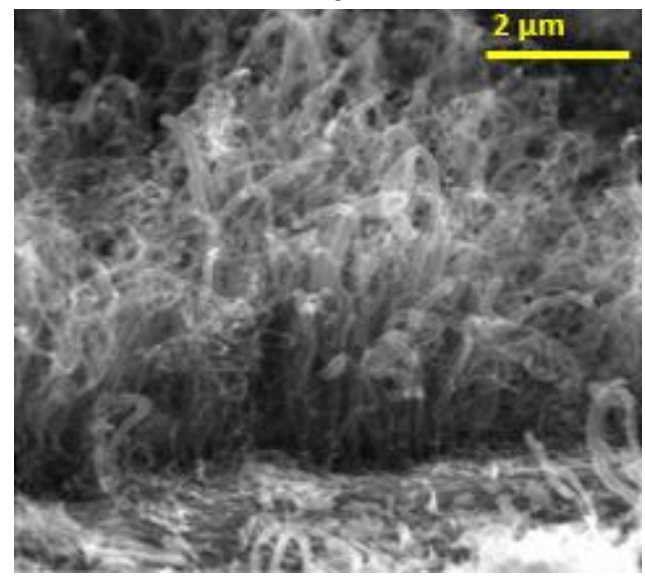

b

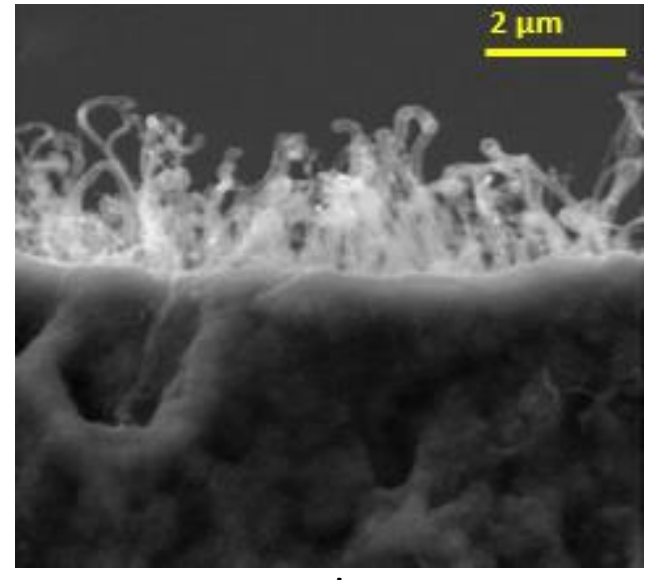

d

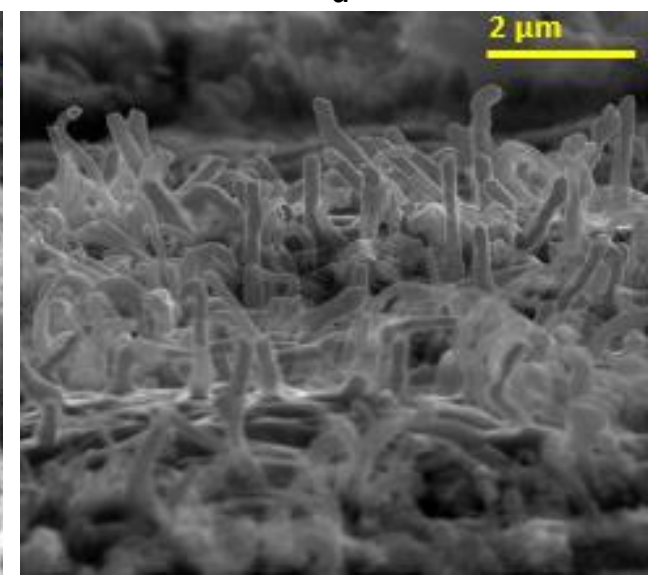

Figure 2. SEM images of MWCNT grown on cobalt-coated stainless steel substrate at $750^{\circ} \mathrm{C}$ for various CVD times and $\mathrm{CoSO}_{4} \cdot 7 \mathrm{H}_{2} \mathrm{O}$ concentrations: (a) $30 \mathrm{~min}, 0.01 \mathrm{M}$, (b) $30 \mathrm{~min}, 0.05 \mathrm{M}$, (c) $30 \mathrm{~min}, 0.15 \mathrm{M}$, and (d) $20 \mathrm{~min}, 0.1 \mathrm{M}$.

\section{Modification of MWCNT with zinc oxide}

Low-density vertically aligned MWCNT were modified by ZnO structures via electrodeposition technique. The potentiostatic method was utilized to synthesize $\mathrm{ZnO} / \mathrm{MWCNT}$ composites by applying 
various potentials in the range of -0.15 to $-1.8 \mathrm{~V}$ for different durations in solutions containing varying concentrations of $\mathrm{Zn}\left(\mathrm{NO}_{3}\right)_{2}$ and $\mathrm{KCl}$. Afterwards, the influence of operating parameters on the morphological and structural properties of the fabricated ZnO-modified MWCNT was investigated.

The electrochemical deposition of zinc oxide from zinc nitrate aqueous solutions at different applied potentials initiates with the reduction of nitrate ions to nitrite and hydroxide ions. The generated hydroxide ions react with zinc ions, leading to the precipitation of zinc hydroxide on the surface of MWCNT, which is spontaneously dehydrated into zinc oxide. These processes can be represented by the following reactions [23];

$$
\begin{aligned}
& \mathrm{NO}_{3}{ }^{-}+\mathrm{H}_{2} \mathrm{O}+2 \mathrm{e}^{-} \rightarrow \mathrm{NO}_{2}{ }^{-}+2 \mathrm{OH}^{-} \\
& \mathrm{Zn}^{2+}+2 \mathrm{OH}^{-} \rightarrow+\mathrm{Zn}(\mathrm{OH})_{2} \\
& \mathrm{Zn}(\mathrm{OH})_{2} \rightarrow \mathrm{ZnO}+\mathrm{H}_{2} \mathrm{O}
\end{aligned}
$$

The electrodeposition potential plays a critical role in determining the morphological structure of ZnO/MWCNT composite. To optimize the potentials suited for the electrodeposition of ZnO onto carbon nanotubes, the potentials of $-0.15,-1,-1.5$, and $-1.8 \mathrm{~V}$ were applied for $20 \mathrm{~min}$ in a solution containing $0.05 \mathrm{M} \mathrm{Zn}\left(\mathrm{NO}_{3}\right)_{2}$ and $0.1 \mathrm{M} \mathrm{KCl}$. The morphologies of the synthesized $\mathrm{ZnO} / \mathrm{MWCNT}$ composites were analyzed by SEM, as shown in Figure 3. Based on Figures 3 (a) and (b), when the electrodeposition potential of $-0.15 \mathrm{~V}$ was applied, the stainless steel substrate and the sidewalls of MWCNTs have a relatively high interfacial tension, leading to an increase of the nucleation energy barrier [24]. Therefore, only a few fine ZnO crystallites can nucleate on the surface of MWCNTs and undergo three-dimensional growth, yielding to formation of micro-sized bundles of ZnO particles that are non-uniformly distributed on the surface. The obtained $\mathrm{ZnO}$ structure does not provide the composite with a high surface area-to-volume ratio which is essential for biosensing applications, and thus is not considered as a favorable sensing platform. Figure 3(c) displays that at the deposition potential of $-1 \mathrm{~V}$, the MWCNTs are uniformly covered with two-dimensional ZnO hexagonal plates that are perpendicular to the sidewalls of the nanotubes. The high-magnification image in Figure 3(d) shows that the adjacent hexagonal plates of $\mathrm{ZnO}$ intercross each other, and create a thin and porous layer with a flake-like structure which is not appropriate for non-enzymatic biosensing applications. As illustrated in Figures $3(\mathrm{e})$ and (f), at the potential of $-1.5 \mathrm{~V}, \mathrm{ZnO}$ is deposited on individual MWCNT as interconnected nanoparticles rather than a thin layer, with a good uniformity and moderate density. The formation of this nanostructure is attributed to the relatively high electrodeposition potential which reduces the interfacial tension of the MWCNT and increases the number of active nucleation sites [25]. Hence, higher number of ZnO crystallites can adsorb and nucleate on the surface of MWCNTs, producing more refined structure of $\mathrm{ZnO}$ nanoparticles with the average diameter of $115 \mathrm{~nm}$. According to Figures 3(g) and (h), a homogeneous array of ZnO nanoparticles is deposited on MWCNT at the potential of $-1.8 \mathrm{~V}$, while the size of ZnO nanoparticles, estimated as $110 \mathrm{~nm}$, does not significantly change as compared to the size of nanoparticles deposited at $-1.5 \mathrm{~V}$. This can be ascribed to the evolution of hydrogen at more negative potentials, which adsorbs on the surface of MWCNT or growing ZnO crystals, thereby suppressing the further adsorption of $\mathrm{Zn}^{2+}$ and $\mathrm{OH}^{-}$ions and hindering the growth of $\mathrm{ZnO}$ nanoparticles. 

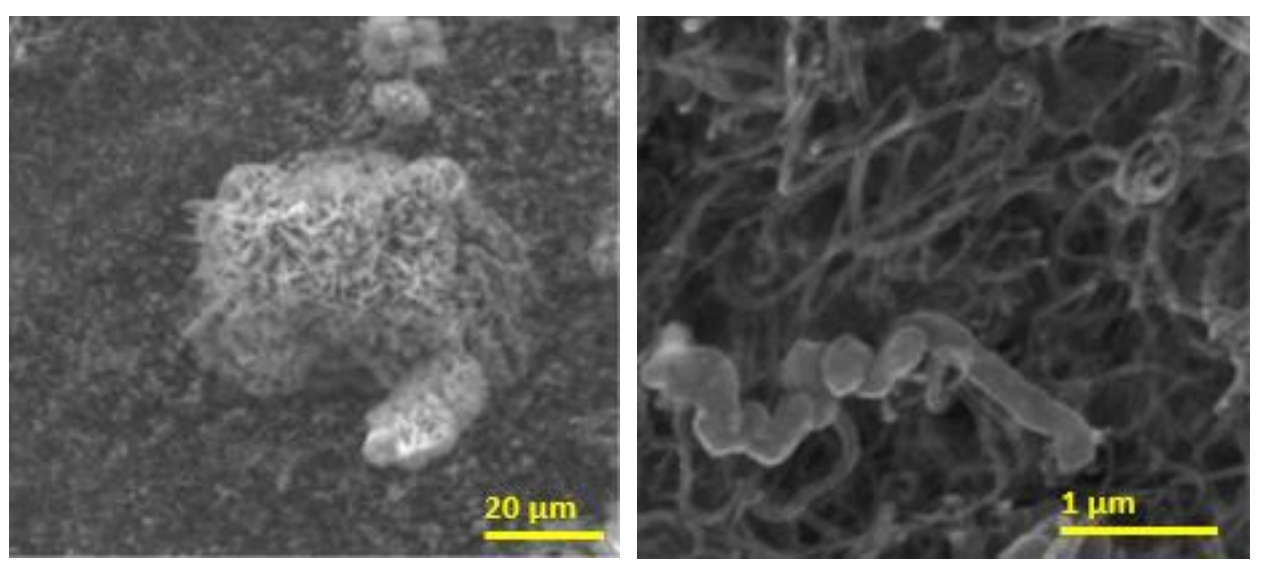

C

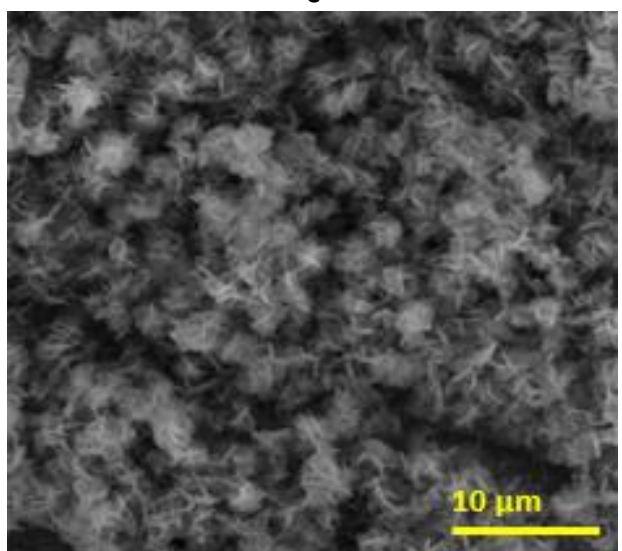

e

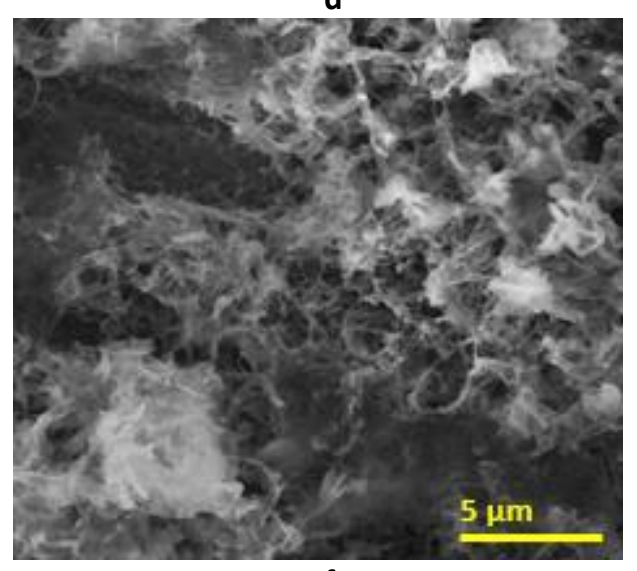

f
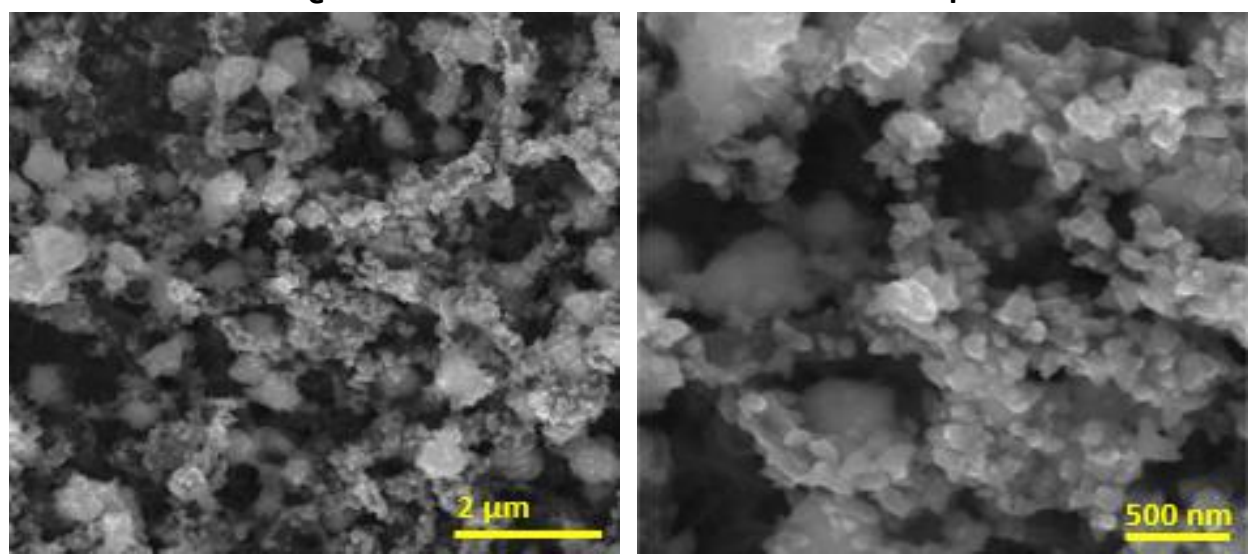

g

h
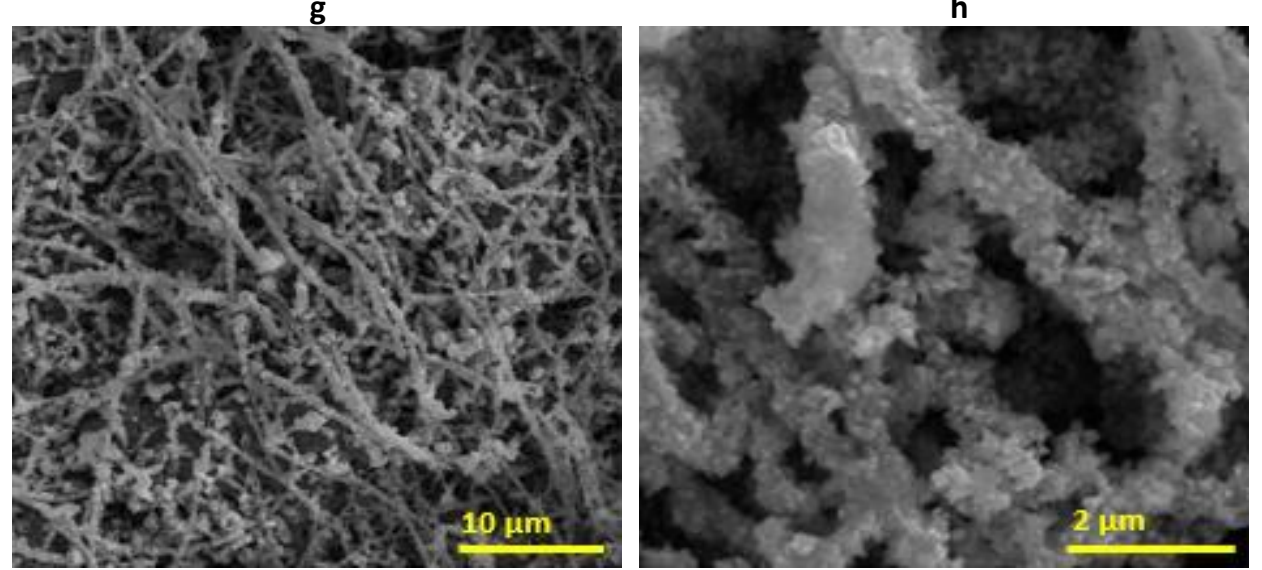

Figure 3. SEM micrographs of ZnO/MWCNT nanocomposites deposited from solutions containing $0.05 \mathrm{M} \mathrm{Zn}\left(\mathrm{NO}_{3}\right)_{2}$ and $0.1 \mathrm{M} \mathrm{KCl}$ during 20 min at the deposition potential ( $\mathrm{V}$ vs. SCE) of: (a), (b) -0.15; (c), (d) -1; (e), (f) -1.5; and (g), (h) -1.8 V vs. SCE. 
Moreover, it can be observed that the density of deposited particles increased at $-1.8 \mathrm{~V}$ due to the higher deposition rate at more negative potentials. Accordingly, the attachment of too many ZnO nanoparticles onto MWCNT may reduce the electronic transfer properties of nanotubes and impair their capability as biosensors [26]. Thus, the potential of $-1.5 \mathrm{~V}$ is selected as the optimal deposition potential.

In order to efficiently tailor the density of $\mathrm{ZnO}$ nanoparticles at the electrodeposition potential of $-1.5 \mathrm{~V}$, the concentrations of $\mathrm{Zn}\left(\mathrm{NO}_{3}\right)_{2}$ and $\mathrm{KCl}$ in the deposition bath were reduced to $0.025 \mathrm{M}$ and $0.05 \mathrm{M}$, respectively, and the deposition time was kept 20 min. Figures 4 (a) and (b) depict the influence of the electrolyte concentration on the surface morphology of ZnO/MWCNT nanocomposites. From these figures it is obvious that lowering the concentrations of zinc nitrate and potassium chloride increases the spacing between $\mathrm{ZnO}$ nanoparticles and reduces the mean diameter of nanoparticles to $90 \mathrm{~nm}$, contributing to the non-enzymatic biosensing properties of the prepared electrode. Nevertheless, nonspherical ZnO particles with sharp facets are not uniformly distributed over the surface of MWCNTs, making it partially uncovered with zinc oxide. Thus, lowering the electrolyte concentration is not an effective approach for decreasing the density of the deposited nanoparticles. To resolve this issue, the deposition time was reduced to $10 \mathrm{~min}$, while the concentration of $\mathrm{Zn}\left(\mathrm{NO}_{3}\right)_{2}$ and $\mathrm{KCl}$ was kept at $0.05 \mathrm{M}$ and $0.1 \mathrm{M}$, respectively. Based on Figures 4(c) and (d), the density of ZnO nanoparticles decreased after shorter electrodeposition time, and the deposited particles are more consistent in size and shape. In this case, most of the particles have a quasi-spherical shape, with a mean diameter of $60 \mathrm{~nm}$, are dispersed evenly on the surface of MWCNT.

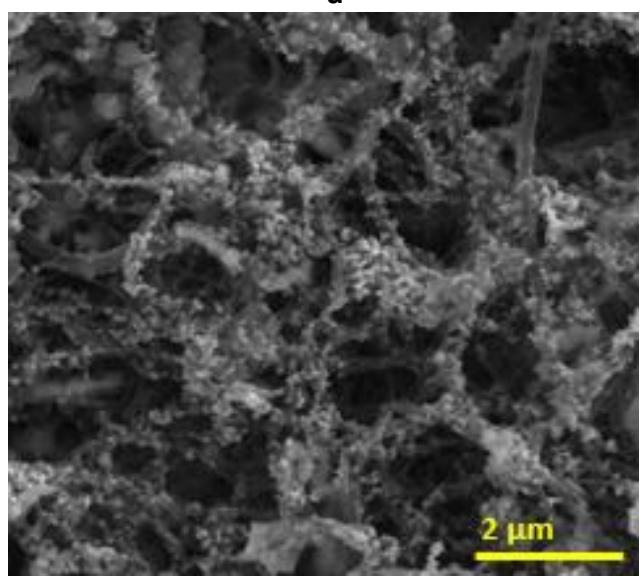

c

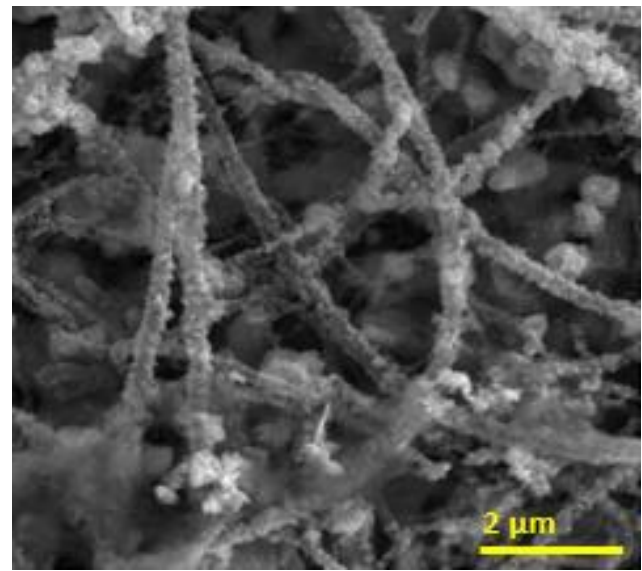

b

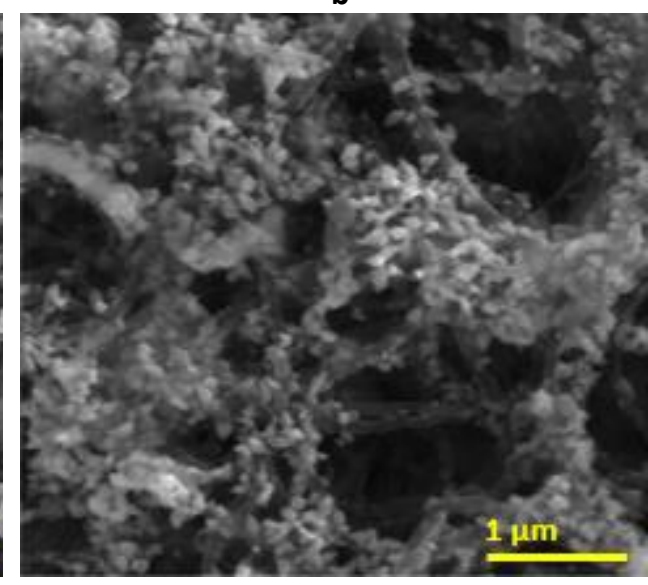

d

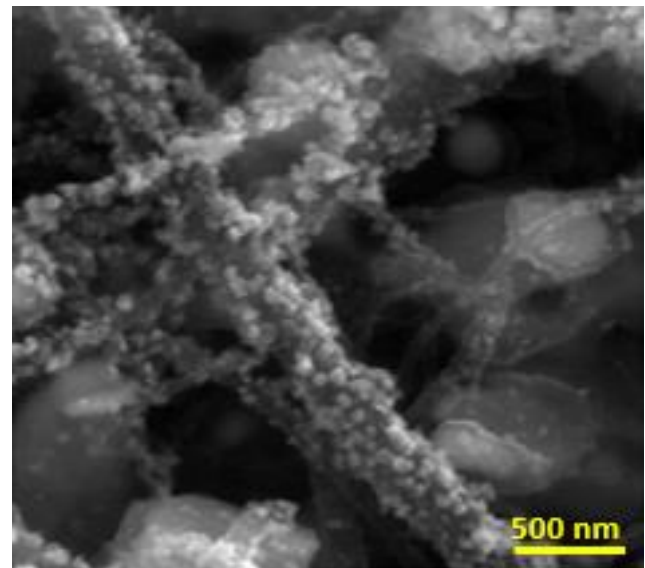

Figure 4. SEM images of ZnO/MWCNT nanocomposites deposited at $-1.5 \mathrm{~V} v \mathrm{vs}$. SCE for: (a), (b) $20 \mathrm{~min}$ in $0.025 \mathrm{M} \mathrm{Zn}\left(\mathrm{NO}_{3}\right)_{2}+0.05 \mathrm{M} \mathrm{KCl}$; (c), (d) $10 \mathrm{~min}$ in $0.05 \mathrm{M} \mathrm{Zn}\left(\mathrm{NO}_{3}\right)_{2}+0.1 \mathrm{M} \mathrm{KCl}$. 
From the above analysis, it is concluded that the surface morphology of ZnO/MWCNT nanocomposites can be optimized if the electrodeposition potential of $-1.5 \mathrm{~V}$ is applied for $10 \mathrm{~min}$ in a solution containing $0.05 \mathrm{M} \mathrm{Zn}\left(\mathrm{NO}_{3}\right)_{2}$ and $0.1 \mathrm{M} \mathrm{KCl}$.

\section{Reinforcement of ZnO/MWCNT nanocomposites with polyaniline}

A polyaniline (PANI) film was deposited on the optimized ZnO/MWCNT-based electrode by sweeping the potential for 6 cycles in the range of -0.2 to $+0.8 \mathrm{~V}$ with a scan rate of $50 \mathrm{mV} \mathrm{s}^{-1}$, in a solution containing $0.025 \mathrm{M}$ aniline and $0.25 \mathrm{M}$ sulfuric acid. The fabricated PANI-reinforced electrode was subsequently dried at room temperature and its surface morphology was examined. Figures 5(a) and (b) demonstrate that electro-polymerization of aniline occurred successfully and a compact layer of the PANI nanofibers perfectly covered ZnO-modified carbon nanotubes, creating an entangled network which can further enhance the electrical conductivity of MWCNTs [27]. Moreover, based on data already reported in the literature [28], it can be concluded that the fabricated PANI/ZnO/MWCNT nanocomposite has a core-shell structure. The effective interaction between $\pi$-bonds in the aromatic ring of the polyaniline and the graphitic structure of carbon nanotubes and zinc oxide nanoparticles causes PANI chains to be adsorbed on the surface of the ZnO/MWCNT nanocomposite, thus forming a tubular PANI shell that surrounds ZnO-modified MWCNT.
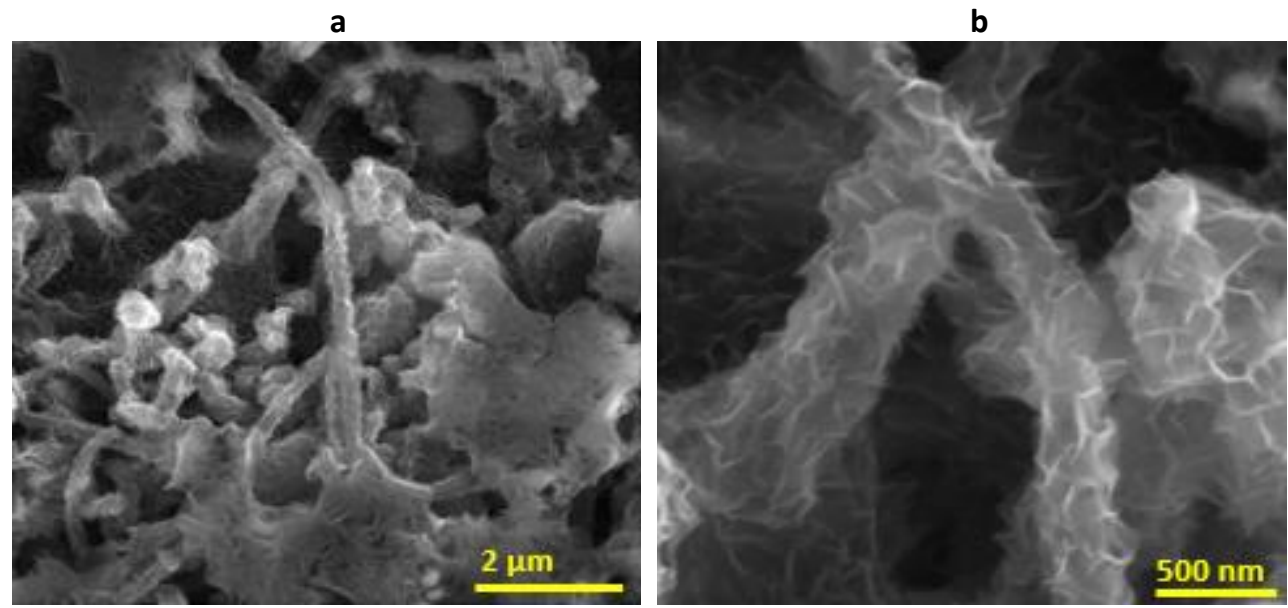

Figure 5. (a) low magnification and (b) high magnification SEM images of PANI/ZnO/MWCNT nanocomposite

\section{Elemental and structural analyses}

The elemental analyses of the optimized ZnO/MWCNT and PANI/ZnO/MWCNT nanocomposites were carried out using EDX measurements, as shown in Figure 6.

a

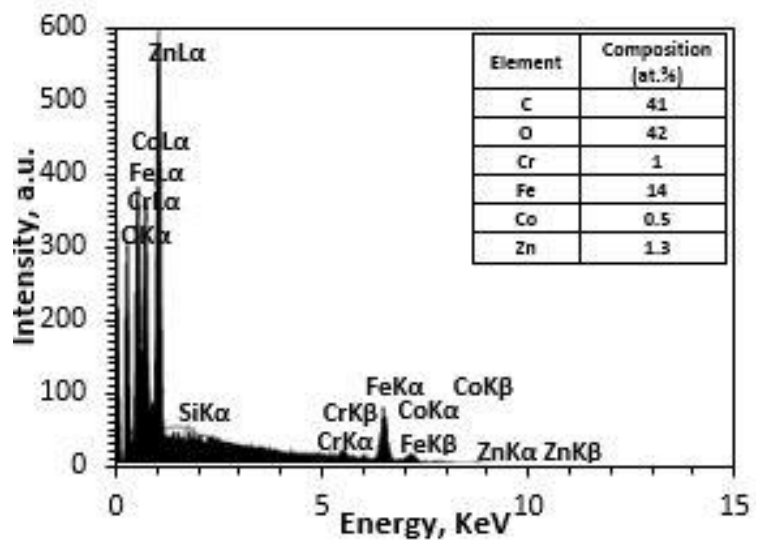

b

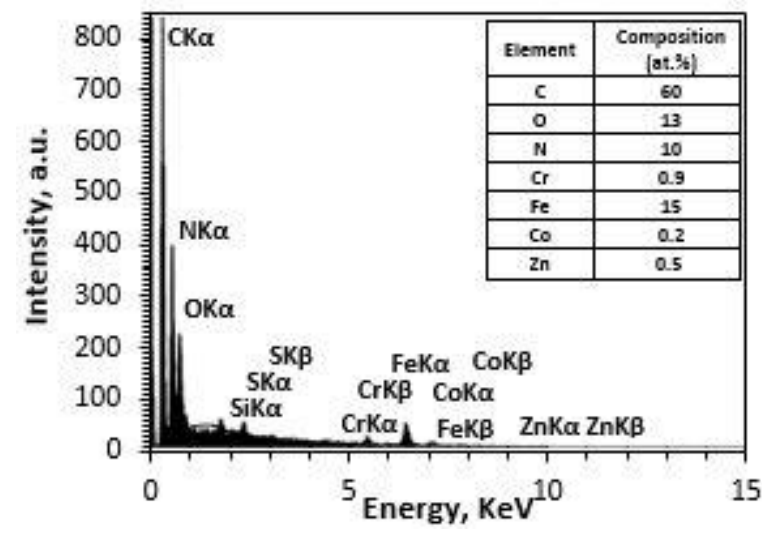

Figure 6. EDX spectra of (a) ZnO/MWCNT and (b) PANI/ZnO/MWCNT nanocomposites 
Figure 6(a) represents the strong peaks of zinc and oxygen elements, confirming the presence of zinc oxide nanoparticles within ZnO/MWCNT nanocomposite. Figure 6(b) exhibits the nitrogen and carbon peaks for PANI/ZnO/MWCNT nanocomposite, and the detected atomic ratios of these two elements correspond to polyaniline according to $\mathrm{C}_{24} \mathrm{H}_{20} \mathrm{~N}_{4}$ formula. However, the EDX method does not enable the detection of hydrogen atoms on polyaniline aromatic rings. The expected peaks for zinc and oxygen can be observed as well, and it can be concluded that the PANI/ZnO/MWCNT nanocomposite sample contains zinc oxide and polyaniline compounds.

The XRD patterns of the optimized ZnO/MWCNT and PANI/ZnO/MWCNT nanocomposites are illustrated in Figure 7. For ZnO/MWCNT nanocomposite, diffraction peaks at $2 \theta=43.1,44.6,50.7$, and $74.5^{\circ}$ correspond to the reflections of (100), (101), (102), and (112) planes of carbon (JCPDS no. 41-1487), respectively, indicating the crystallinity of the multi-walled MWCNTs. The graphitic peak at $2 \theta=26.4^{\circ}$ can be attributed to the (002) reflection of MWCNT while it is relatively broad as compared to other carbon peaks. The lower intensity of this peak is indicative for a less number of adjacent graphite layers present in MWCNTs, and increased degree of nanotubes alignment [29,30]. Moreover, the peaks at $2 \theta$ values of $30.75,36.20,56.45,62.72$, and $66.25^{\circ}$ are assigned to the (100), (101), (110), (103), and (200) crystal planes of ZnO nanoparticles, respectively. These diffraction peaks can be indexed to the standard hexagonal wurtzite-structured ZnO nanoparticles (JCPDS no. 36-1451). For the PANI/ZnO/MWCNT nanocomposite, a sharp diffraction peak emerges at $2 \theta$ value of $26.28^{\circ}$ due to an overlap between (002) peak of MWCNT and (200) peak of PANI, resulting in an intense peak of the composite. This result further confirms that a homogeneous coating of PANI nanofibers is well dispersed on Zn-modified MWCNTs, as has already been demonstrated by the SEM images in Figure 5. This XRD pattern also exhibits a characteristic peak corresponding to the (311) plane of cobalt catalyst nanoparticles (JCPDS 43-1003) that are encapsulated into MWCNT during their synthesis.

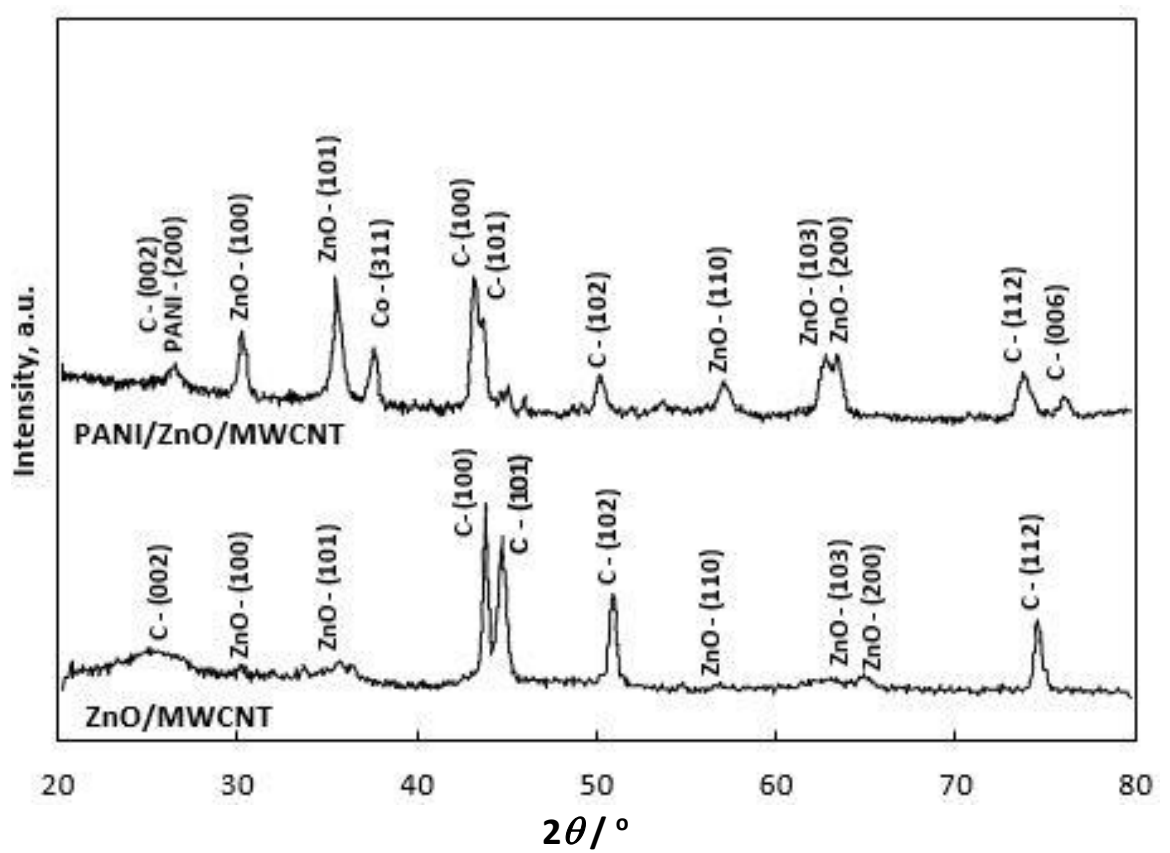

Figure 7. XRD patterns of ZnO/MWCNT and PANI/ZnO/MWCNT nanocomposites.

Non-enzymatic electrochemical detection of glucose

The electrocatalytic activities of the unmodified MWCNT, ZnO/MWCNT, and PANI/ZnO/MWCNT electrodes towards the oxidation of glucose were evaluated using CV measurements in the potential 
range of 0 to $1.5 \mathrm{~V}$. Figure 8 (a) displays the obtained CVs at the examined surfaces in a solution containing $100 \mathrm{mM} \mathrm{NaOH}$ and $10 \mathrm{mM}$ glucose at a scan rate of $100 \mathrm{mV} \mathrm{s}^{-1}$. A large oxidation wave with a peak potential at about $0.85 \mathrm{~V}$ is sensed by the unmodified MWCNTs due to the electrocatalytic oxidation of glucose by carbon nanotubes with minor contributions from Co catalyst nanoparticles. It is worth mentioning that during the synthesis of MWCNT arrays on Co catalyst-coated stainless steel substrate, cobalt is likely to be trapped in graphite-like planes within the carbon nanotube or along the tube axis, thereby promoting the electrochemical oxidation of glucose on MWCNTs [31].

a

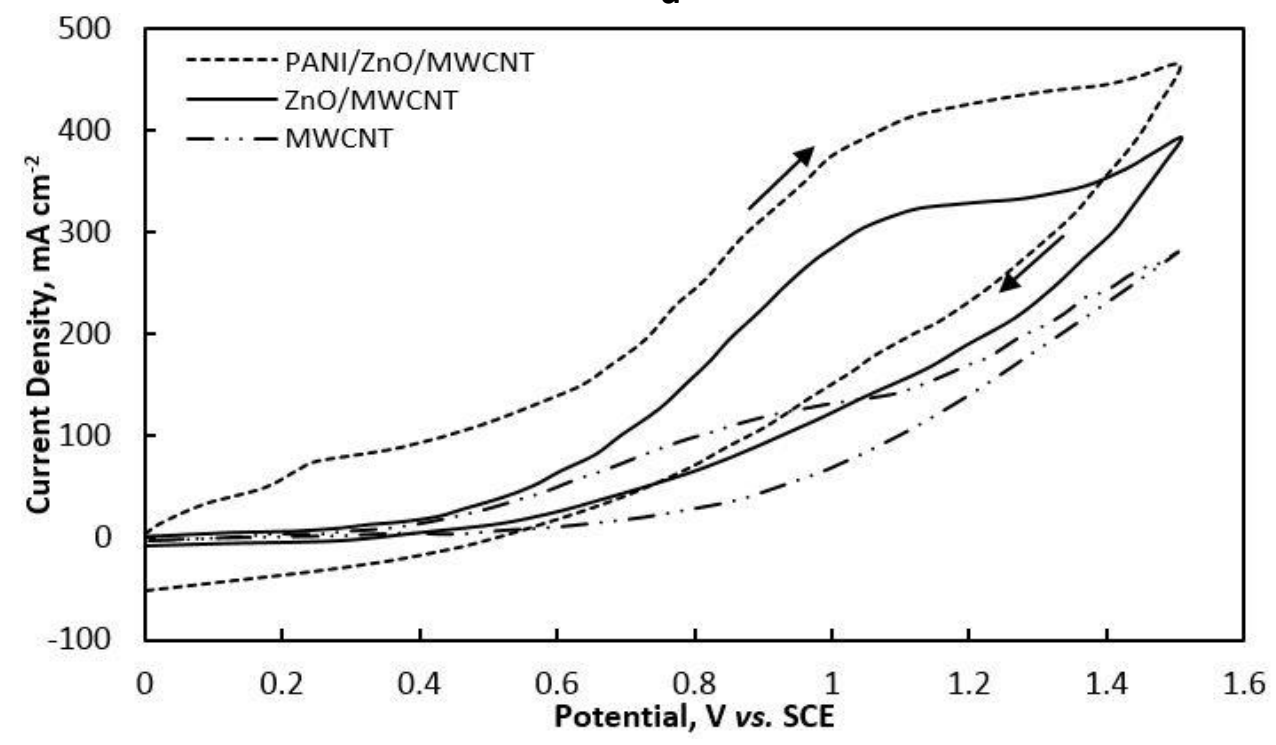

b

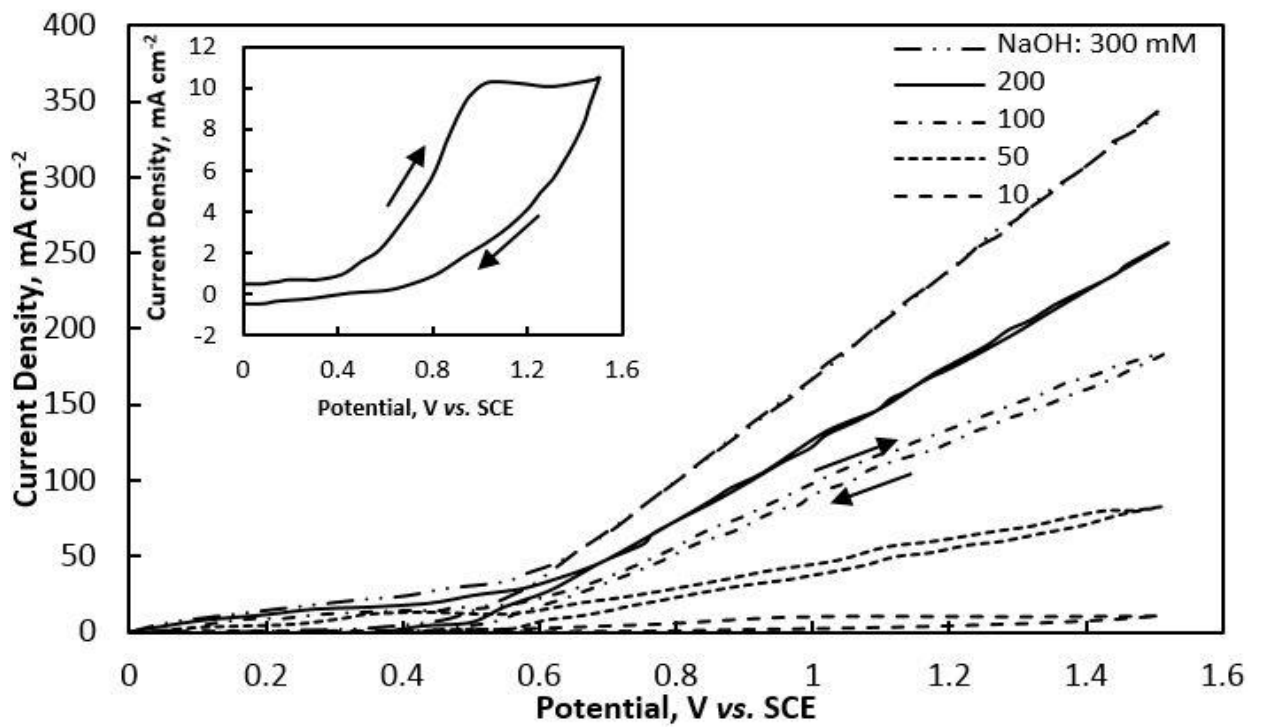

Figure 8. Cyclic voltammetric responses at scan rate of $100 \mathrm{mV} \mathrm{s}^{-1}$ of: (a) MWCNT, ZnO/MWCNT and PANI/ZnO/MWCNT electrodes in $100 \mathrm{mM} \mathrm{NaOH}+10 \mathrm{mM}$ glucose solution and (b) PANI/ZnO/MWCNT electrode in a solution containing various concentrations of $\mathrm{NaOH}$ and $1 \mathrm{mM}$ glucose (Inset shows the amplified CV curve obtained in a solution containing $10 \mathrm{mM} \mathrm{NaOH}$ ).

For $\mathrm{ZnO} / \mathrm{MWCNT}$ electrode, the anodic current starts to increase at about $0.42 \mathrm{~V}$ with the appearance of an obvious oxidation peak at around 1.1 V. This electrode shows a higher current response and a faster electron transfer kinetics as compared to the unmodified MWCNT electrode due to the electrocatalytic active sites provided by ZnO nanostructures. ZnO nanoparticles play a crucial role in the oxidation of glucose; however, they do not directly react with glucose in the nonenzymatic sensors but they accelerate the electron transfer from glucose to MWCNT. Thus, the 
electron-transfer ability and the electro-catalytic performance of MWCNT towards the oxidation of glucose can be significantly enhanced by incorporating ZnO nanoparticles. The PANI/ZnO/MWCNT electrode produces an anodic current at $0 \mathrm{~V}$ followed by a negligible peak at $0.25 \mathrm{~V}$ which is attributed to the formation of the emeraldine salt [32]. With the increase of the potential in the anodic sweep, an oxidation wave appears due to the oxidation of glucose with a peak potential at about $1.08 \mathrm{~V}$. The higher oxidation currents from the PANI/ZnO/MWCNT electrode in response to the glucose oxidation and the significant increase in the peak current as compared to the ZnO/MWCNT and unmodified MWCNT electrodes are ascribed to the synergistic effect of PANI, ZnO, and MWCNTs. Moreover, the conducting behavior of PANI nanofibers with large surface area and fast charge transport ability can efficiently enhance the sensitivity of the fabricated glucose biosensor [33]. The absence of cathodic peaks in the CVs indicates that the oxidation of glucose on all the three electrodes is completely irreversible.

The glucose sensing behavior of the PANI/ZnO/MWCNT electrode was further studied in $\mathrm{NaOH}$ solutions of different concentrations in the presence of $1 \mathrm{mM}$ glucose, as shown in Figure 8 (b). This figure demonstrates that in alkaline media, the rates of electron transfer reactions of glucose occurring at the electrode increase with $\mathrm{NaOH}$ concentration (i.e. $\mathrm{pH}$ value) in the range of 10 to $300 \mathrm{mM}$. However, high $\mathrm{NaOH}$ concentrations generate many intermediate reactants that might interact with the electrode materials and hinder the glucose reaction [34], so that oxidation peaks cannot be clearly observed in the CVs. Thus, the enhanced current responses and electron transfer rates recorded for higher concentrations of $\mathrm{NaOH}$ impair the detection capability of the sensor and are not beneficial for the sensing performance of the electrode. Based on the inset in Figure 8(b), the oxidation peak is more pronounced at low $\mathrm{NaOH}$ concentration of $10 \mathrm{mM}$, and the sensitivity of the electrode is much higher than that obtained in solutions of higher concentrations. Hence, $10 \mathrm{mM} \mathrm{NaOH}$ solution is selected as the optimized supporting electrolyte for the electrocatalytic oxidation of glucose.

Further assessment of the glucose oxidation process was conducted by exploring the influence of different scan rates $\left(10,50,100,300\right.$, and $\left.500 \mathrm{mV} \mathrm{s}^{-1}\right)$ on the linear sweep voltammetric response of the PANI/ZnO/MWCNT electrode in a solution containing $10 \mathrm{mM} \mathrm{NaOH}$ and $1 \mathrm{mM}$ glucose. Figure 9(a) exhibits that upon increasing the scan rates, the oxidation peak current densities increase, while the glucose oxidation peaks shift to more positive potentials. The inset in this figure illustrates a linear relationship between the anodic peak current density $\left(i_{p}\right)$ and the square root of the scan rate $\left(v^{1 / 2}\right)$. The regression line equation is: $i_{p} / \mathrm{mA} \mathrm{cm}^{-2}=0.5756 v^{1 / 2} /\left(\mathrm{mV} \mathrm{s}^{-1}\right)^{1 / 2}+2.343 ; \mathrm{R}^{2}=0.9968$. These results reveal that the oxidation process is controlled by diffusion of glucose molecules to the electrode surface, rather than adsorption. The oxidation peaks in Figure 9 (a) can be ascribed to the following reaction [35]:

glucose $+\mathrm{O}_{2} \rightarrow$ gluconolactone $+\mathrm{H}_{2} \mathrm{O}_{2}$

As the potential is swept to more oxidizing values, gluconolactone is spontaneously converted to gluconic acid [36] according to:

gluconolactone $\rightarrow$ gluconate ${ }^{-}+\mathrm{H}^{+}$

Figure 9(b) illustrates LSVs of PANI/ZnO/MWCNT electrode recorded at the scan rate of $100 \mathrm{mV} \mathrm{s}^{-1}$ in $10 \mathrm{mM} \mathrm{NaOH}$ solution containing different concentrations of glucose from 0.1 to $6 \mathrm{mM}$. It can be observed that with an increase in the glucose concentration, the oxidation peak current density at about $1.08 \mathrm{~V}$ shows an increasing trend. As depicted in the inset in Figure 9 (b), the variation of the peak current density vs. glucose concentration exhibits two separate linear regions in the concentration ranges of 0.1-1 mM and 1-6 mM, respectively. The corresponding regression equations 
are $i_{\mathrm{p}} / \mathrm{mA} \mathrm{cm}{ }^{-2}=7.8307 \mathrm{c} / \mathrm{mM}+2.1088\left(\mathrm{R}^{2}=0.995\right)$ and $i_{\mathrm{p}} / \mathrm{mA} \mathrm{cm} \mathrm{cm}^{-2}=1.6731 \mathrm{c} / \mathrm{mM}+$ $+8.454\left(R^{2}=0.998\right)$, respectively. From the slopes of the corresponding calibration plots, the sensitivity of the sensor is calculated to be $7.8307 \mathrm{~mA} \mathrm{mM}^{-1} \mathrm{~cm}^{-2}$ and $1.6731 \mathrm{~mA} \mathrm{mM}^{-1} \mathrm{~cm}^{-2}$ for the glucose concentration between 0.1 to $1 \mathrm{mM}$ and 1 to $6 \mathrm{mM}$, respectively. Based on the signal to noise ratio of 3 , the detection limit of $0.1 \mu \mathrm{M}$ was obtained. The fabricated PANI/ZnO/MWCNT sensor electrode shows better performance and higher sensitivity for the non-enzymatic determination of glucose in comparison to other previously reported non-enzymatic glucose biosensors that focused on carbon nanotubes, $\mathrm{ZnO}$ nanoparticles, and PANI nanofibers-modified electrodes [37-39]. Such enhanced sensitivity can be attributed to the unique properties of carbon nanotubes, zinc oxide nanoparticles, and polyaniline nanofibers and their synergistic effect which results in a significant improvement of the electrochemical activity of the modified electrode for the detection of glucose.

a

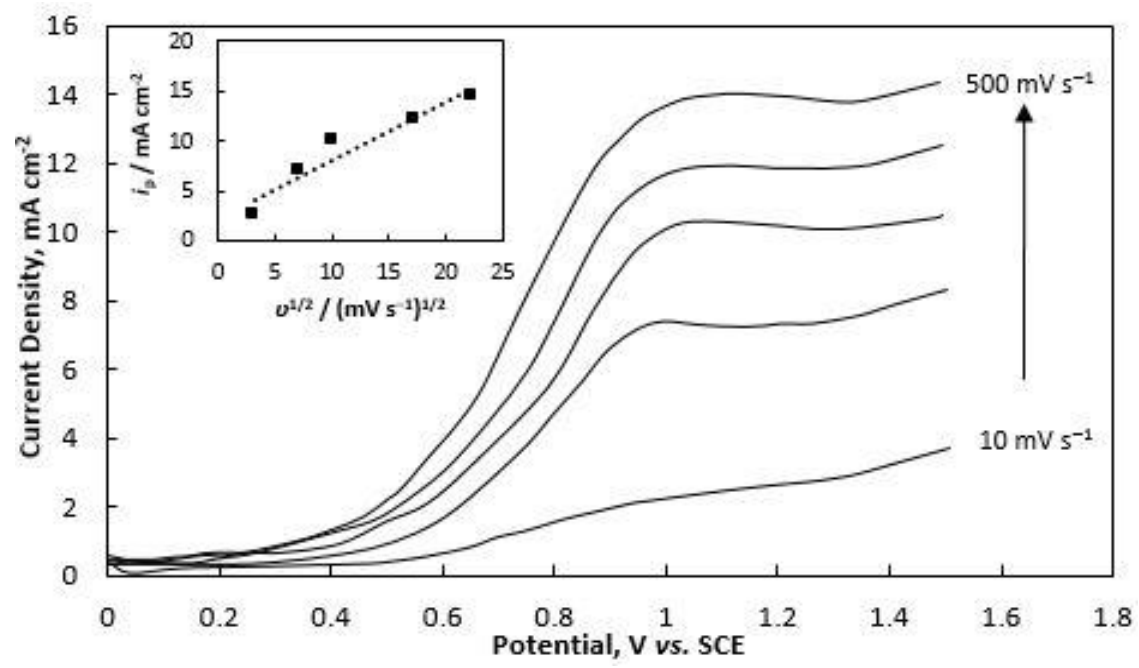

b

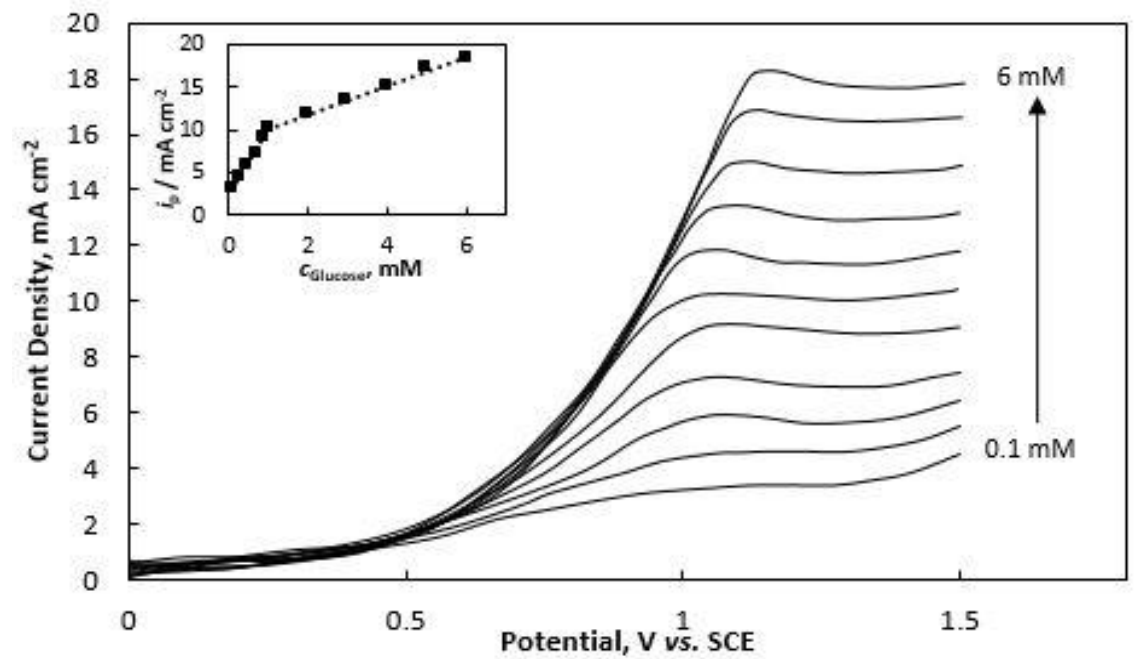

Figure 9. Linear sweep voltammograms of PANI/ZnO/MWCNT electrode in $10 \mathrm{mM} \mathrm{NaOH}$ solution containing (a) $1 \mathrm{mM}$ glucose solution at different scan rates from 10 to $500 \mathrm{mV} \mathrm{s}^{-1}$ (Inset shows the oxidation peak current density vs. the square root of the scan rate), (b) different concentrations of glucose from 0.1 to $6 \mathrm{mM}$ at the scan rate of $100 \mathrm{mV} \mathrm{s}^{-1}$ (Inset shows oxidation peak current density vs. glucose concentration)

Figure 10 presents the steady-state current-time response of the PANI/ZnO/MWCNT electrode in $10 \mathrm{mM} \mathrm{NaOH}$ with the addition of $0.1 \mathrm{Mm}$ glucose at the oxidation potential of $1.08 \mathrm{~V}$. The response time (i.e. the time required to reach $95 \%$ of the maximum steady-state current) is $<5 \mathrm{~s}$, 
indicating rapid current response of the electrode to the injection of glucose due to the facile electron transfer process through the PANI/ZnO/MWCNT nanocomposite.

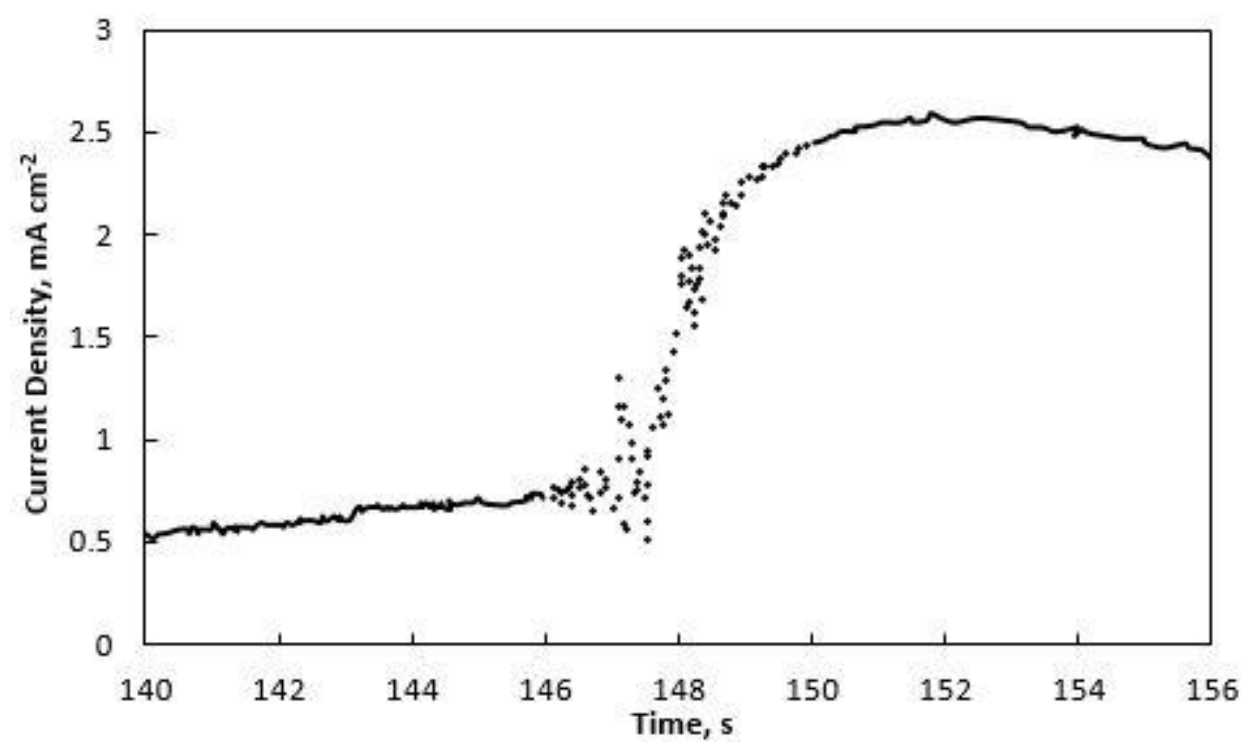

Figure 10. Amperometric response of PANI/ZnO/MWCNT electrode at $1.08 \mathrm{~V} v \mathrm{vs}$. SCE in $10 \mathrm{mM}$ $\mathrm{NaOH}$ with addition of $0.1 \mathrm{mM}$ glucose

The stability of the PANI/ZnO/MWCNT electrode was explored by measuring its current response within two weeks. The sensor was stored in air at ambient conditions and its current response to $1 \mathrm{mM}$ glucose was tested every day. After 15 days of storage, the current response of the electrode only decreased $6.3 \%$ compared to the initial response, revealing the long-term stability of the developed biosensor. The reproducibility measurement was carried out by comparing the current responses of six modified electrodes fabricated under the same conditions towards the detection of $1 \mathrm{mM}$ glucose dissolved in $10 \mathrm{mM} \mathrm{NaOH}$. The relative standard deviation (RSD) of responses was estimated to be $3.2 \%$, indicating the satisfactory reproducibility and reliability of the synthesized sensor.

\section{Conclusions}

In this work, we successfully developed a non-enzymatic electrochemical glucose sensor based on PANI/ZnO/MWCNT ternary nanocomposite. In order to decrease the density of MWCNT and synthesize aligned nanotubes by thermal CVD process on cobalt-coated substrates, $\mathrm{CoSO}_{4} \times 7 \mathrm{H}_{2} \mathrm{O}$ concentration of $0.1 \mathrm{M}$ and CVD reaction time of 20 min were selected to yield the formation of perfectly aligned arrays of low-density MWCNT that were efficient for biosensing applications. The optimized ZnO/MWCNT nanocomposite, in which $60 \mathrm{~nm}$ quasi-spherical $\mathrm{ZnO}$ nanoparticles were uniformly dispersed on the surface of nanotubes, was fabricated at the electrodeposition potential and time of $-1.5 \mathrm{~V}$ and $10 \mathrm{~min}$, respectively, in a solution containing $0.05 \mathrm{M} \mathrm{Zn}\left(\mathrm{NO}_{3}\right)_{2}$ and $0.1 \mathrm{M} \mathrm{KCl}$. The electrochemical sensing properties of ZnO/MWCNT nanocomposite was improved by a thin layer of PANI through the potential cycling technique, and SEM, EDX, and XRD confirmed the effective structural modification of the surface by PANI nanofibers. CV measurements conducted in solutions containing glucose and sodium hydroxide revealed that the electrocatalytic performance of MWCNT towards the oxidation of glucose can be significantly enhanced by incorporating ZnO nanoparticles and PANI nanofibers. The oxidation of glucose on the designed PANI/ZnO/MWCNT sensor involved a diffusion-controlled process, with sensitivities of $7.8307 \mathrm{~mA} \mathrm{mM} \mathrm{mm}^{-1} \mathrm{~cm}^{-2}$ and 
$1.6731 \mathrm{~mA} \mathrm{mM} \mathrm{mm}^{-1} \mathrm{~cm}^{-2}$ for the glucose concentrations between 0.1 to $1 \mathrm{mM}$ and 1 to $6 \mathrm{mM}$, respectively, and $0.1 \mathrm{mM}$ limit of detection. The fabricated ternary nanocomposite-based sensor exhibited fast response time $<5 \mathrm{~s}$, as well as high stability of $93.7 \%$ and reproducibility of $3.2 \%$, thereby validating the unique capabilities of the designed PANI/ZnO/MWCNT electrode as an electrochemical sensing platform for non-enzymatic glucose detection.

Acknowledgements: This research was financially sponsored by the Department of Materials Science and Engineering at Sharif University of Technology.

References

[1] D. Bruen, C. Delaney, L. Florea, D. Diamond, Sensors 17 (2017) 1866-1887.

[2] T. Alsufyani, S. A. Fadlallah, Sensing and Bio-Sensing Research 14 (2017) 7-16.

[3] C. Wei, C. Cheng, Y. Cheng, Y. Wang, Y. Xu, W. Du, H. Pang, Dalton Transactions 44 (2015) 1727817285.

[4] R. Sukor, S. Jinap, F. Asilah, F. A. Bakr, International Food Research Journal 23 (2016) 1849-1856.

[5] L. Zhao, L. Wang, Y. Zhang, S. Xiao, F. Bi, J. Zhao, G. Gai, J. Ding, Polymers 9 (2017) 255-275.

[6] C. Espro, S. G. Leonardi, A. Bonavita, S. Galvagno, G. Neri, Sensors 431 (2017) 90-96.

[7] D. W. Hwang, S. Lee, M. Seo, T. D. Chung, Analytica Chimica Acta 1033 (2018) 1-34.

[8] Y. Hu, X. Niu, H. Zhao, M. Lan, Electrochimica Acta 165 (2015) 383-389.

[9] I. Pötzelberger, A. Mardare, A. W. Hassel, Applied Surface Science 417 (2017) 48-53.

[10] B. K. Jena, C. R. Raj, Chemistry: A European Journal 12 (2006) 2702-2708.

[11] T. M. B. F. Oliveira, S. Morais, Applied Sciences 8 (2018) 1925-1943.

[12] Y. Liu, D. Yu, C. Zeng, Z. Miao, L. Dai, Langmuir 26 (2010) 6158-6160.

[13] P. Yáñez-Sedeño, J. M. Pingarrón, J. Riu, F. X. Rius, Trends in Analytical Chemistry 29 (2010) 939-953.

[14] S. Mohajeri, A. Dolati, S. S. Rezaie, Journal of Chemical Sciences 131 (2019) 21-38.

[15] C. Oncel, Y. Yurum, Fullerenes, Nanotubes and Carbon Nanostructures 14 (2006) 17-37.

[16] J. G. Manjunatha, Journal of Electrochemical Science and Engineering 7 (2017) 39-49.

[17] R. Prasad, B. R. Bhat, Sensors and Actuators, B: Chemical 220 (2015) 81-90.

[18] G. K. Nezhad, A. Sarkary, Z. Khorablou, P. S. Dorraji, Iranian Journal of Pharmaceutical Research 17 (2018) 52-62.

[19] X. Zhu, I. Yuri, X. Gan, I. Suzuki, G. Li, Biosensors \& Bioelectronics 22 (2007) 1600-1604.

[20] S. B. Valid, B. Botka, K. Kamarás, A. Zeng, S. Yitzchaik, Carbon 48 (2010) 2773-2781.

[21] H. Zhong, R. Yuan, Y. Chai, Y. Zhang, C. Wang, F. Jia, Microchimica Acta 176 (2012) 389-395.

[22] C. O. Santana, E. F. Southgate, J. P. B. G. Mendes, J. Dweck, E. M. Alhadeff, N. I. B. Ramirez, Journal of Electrochemical Science and Engineering 4 (2014) 165-175.

[23] W. D. Zhang, Y. Wen, S. M. Liu, W. C. Tjiu, G. Q. Xu, L. M. Gan, Carbon 40 (2002) 1981-1989.

[24] M. Izaki, T. Omi, Applied Physics Letters 68 (1996) 2439-2440.

[25] F. Xu, Y. Lu, Y. Xie, Y. Liu, Materials \& Design 30 (2009) 1704-1711.

[26] S. Mohajeri, A. Dolati, S. H. Daryan, Journal of Electrochemical Science and Engineering 8 (2018) 205217.

[27] C. Zhang, G. Wang, M. Liu, Y. Feng, Z. Zhang, B. Fang, Electrochimica Acta 55 (2010) 2835-2840.

[28] S. B. Kondawar, M. D. Deshpande, International Journal of Composite Materials 2 (2012) 32-36.

[29] I. Cesarino, Electroanalysis 23 (2011) 2586-2593.

[30] D. K. Singh, P. K. Iyer, P. K. Giri, Diamond and Related Materials 19 (2010) 1281-1288.

[31] A. Cao, C. Xu, J. Liang, D. Wu, B. Wei, Chemical Physics Letters 344 (2001) 13-17.

[32] J. S. Ye, Y. Wen, W. D. Zhang, L. M. Gan, G. Q. Xu, F. S. Sheu, Electrochemistry Communications 6 (2004) 66-70.

[33] S. Malhotra, Y. Tang, P. K. Varshney, Analytical \& Bioanalytical Electrochemistry 10 (2018) 699-715.

[34] Y. Qiao, C. Li, L. S. J. Bao, Q. L. Bao, Journal of Power Sources 170 (2007) 79-84.

[35] J. Yang, L. C. Jiang, W. D. Zhang, S. Gunasekaran, Talanta 82 (2010) 25-33.

[36] H. Yang, C. Gong, L. Miao, F. Xu, International Journal of Electrochemical Science 12 (2017) 49584969. 
[37] M. H. Asif, S. M. U. Ali, O. Nur, M. Willander, C. Brännmark, P. Strålfors, U. H. Englund, F. Elinder, B. Danielsson, Biosensors \& Bioelectronics 25 (2010) 2205-2211.

[38] Z. Zhu, L. G. Gancedo, A. J. Flewitt, H. Xie, F. Moussy, W. I. Milne, Sensors 12 (2012) 5996-6022.

[39] K. Singh, A. Umar, A. Kumar, Science of Advanced Materials 4 (2012) 994-1000.

[40] K. Ghanbari, Z. Babaei, Analytical Biochemistry 498 (2016) 37-46.

(C)2019 by the authors; licensee IAPC, Zagreb, Croatia. This article is an open-access article distributed under the terms and conditions of the Creative Commons Attribution license (http://creativecommons. org/licenses/by/4.0/) 